\title{
Special Considerations in the Management of HIV Infection in Pregnancy
}

\author{
Chi Dola, Sean Kim and Juliet Tran \\ Department of Obstetrics and Gynecology, Tulane University School of Medicine \\ New Orleans, Louisiana
}

USA

\section{Introduction}

In the industrialized world, significant development and interventions were made since the HIV epidemic and they contributed to improved maternal health and low perinatal transmission rates. However, not all questions about this infection in pregnancy were answered. At times, obstetric health care providers for HIV-infected pregnant women were faced with certain clinical situations where there was limited available data to help direct treatment planning. This chapter will discuss recent data on various special considerations encountered in the management of HIV infection in pregnancy.

\section{Apparent lack of prenatal care and the lack of knowledge of available treatment to decrease perinatal transmission among HIV-infected women}

Vertical transmission of HIV infection was significantly reduced by offering HIV testing to pregnant women and implementing the Pediatrics AIDS Clinical Trials Group (PACTG) protocol 076 (Connor et al., 1994). The success of this protocol was dependent on women seeking prenatal care, where they were offered HIV screening and appropriate treatment for affected pregnancies and their newborns. However, HIV-infected women often do not obtain prenatal care. As a whole, $5-10 \%$ of women in the United States receive inadequate or no prenatal care (Kogan et al., 1998). HIV-infected women are even less likely to seek prenatal care. According to a study by Minkoff et al., 50\% of HIV-infected women who gave birth at a municipal hospital in New York City did not have prenatal care (Minkoff et al., 1990). In a survey of HIV-infected women in Philadelphia, only a third of these pregnant women reported adequate prenatal care and $20 \%$ had no prenatal care (Turner et al., 1996).

Additionally, these women often failed to disclose their HIV infectious status when they presented for labor and delivery. Fifty percent of the women with inadequate prenatal care were actually aware of their HIV infection but did not choose to disclose to their caretaker when they presented for delivery at the Medical Center of LA in New Orleans (Centers for Disease Control and Prevention [CDC], 2004). This troubling data implies that many HIVinfected women unknowingly, as a consequence of a lack of knowledge, infect their unborn children despite the availability of treatments to reduce vertical transmission (Dola et al., 2010). These findings stress the importance of educating the public on the currently available interventions to reduce vertical transmission of HIV infection. 
One of the barriers to decreasing perinatal transmission is that HIV-infected women do not obtain early prenatal care and thus exclude themselves from available interventions. Heath care providers must understand why HIV infected women are less likely to utilize prenatal services. Lancioni et al. reported that issues normally encountered in women without prenatal care - such as transportation, lack of child care, lack of insurance, and scheduling of appointments - were not found to be the reason why HIV infected women do not seek prenatal care. Rather, these women opted out of prenatal services because they feared the risk of disclosure and the anticipated anger from health care providers because they chose to continue their pregnancy (Lancioni et al., 1999). Eliminating the social stigma about HIV infection and educating health care providers about these women's fears and concerns could help reduce the barriers in seeking prenatal care (Dola et al., 2010).

\section{Limitations of benefits of rapid HIV testing in labor and delivery}

In the United States, approximately 144 - 226 infants are infected annually with HIV (CDC, 2007). Many of these infants were born of mothers who were not tested early in pregnancy or did not receive the appropriate prophylaxis treatment (CDC, 2007). Approximately a quarter of all people currently infected with HIV are not aware of their infectious status (Marks et al, 2006). Therefore, HIV screening during prenatal care is a necessity for the success of PACTG protocol 076. In addition, there is a high rate of HIV infection amongst women without prenatal care (Lindsay et al., 1991). Thus, those who most need it are excluded from the benefits of the PACTG protocol 076 and other obstetrical interventions to decrease perinatal transmission.

Rapid HIV testing is now available to allow undiagnosed HIV-infected women one last vital opportunity to be tested for the infection and to decrease the risk of transmitting the disease to their newborns. By virtue of the fast availability of the rapid HIV test result, it is hoped that interventions can be instituted to decrease perinatal transmission. If a woman tested reactive on the rapid HIV test, she will be counseled appropriately and if agreed, she will be administered zidovudine prophylaxis during labor along with obstetrical interventions, and her neonate will receive prophylactic zidovudine after birth. This abbreviated regimen of zidovudine has been shown to be cost-effective (Stringer et al., 1999) and can decrease vertical transmission (Wade et al., 1998). Studies by Wade et al. show a reduction of vertical HIV transmission to $10 \%$ when zidovudine prophylaxis begins intrapartum compared to $27 \%$ in those without any treatment (Wade et al., 1998).

Rapid HIV testing is an excellent concept to allow undiagnosed HIV-infected women one last chance to decrease the risk of infecting their newborn, however, the benefits of rapid HIV tests may not be fully appreciated due to a large percentage of these women presenting in advanced labor, after rupture of membranes, or when they deliver shortly after arrival to the labor unit. Dola et al. retrospectively analyzed 350 parturients without prior prenatal care at their institution who presented to the labor unit with unknown HIV serostatus (Dola et al., 2010). These women often presented in active labor with cervical dilation of $\geq 5 \mathrm{~cm}$ (48.6\%); another $15.2 \%$ presented at complete cervical dilation of 10 centimeters, and $43 \%$ presented after ruptured membranes. The benefit of early detection of HIV infection via rapid testing may be less obvious in these women as perinatal transmission might already have occurred. Another $5.5 \%$ of these women even missed the benefits of rapid HIV testing by delivering their baby prior to their arrival to the hospital. It could be postulated that no benefit can be gained from a rapid HIV test result to direct effective management of these 
patients during their labor and delivery (Dola et al., 2010). However, early oral zidovudine treatment for the newborn can be facilitated by early detection of the infection by rapid HIV testing on admission. Even so, recent studies reported conflicting data regarding the effectiveness of administering only zidovudine prophylaxis to neonates after delivery (Wade et al., 1998; Fiscus et al., 1999).

Although results from rapid HIV testing is readily available - the median turn-around time is 66 minutes based on the CDC-sponsored MIRIAD Study (Bulterys et al.,2004), or 45 minutes with the OraQuick Rapid HIV-1 Antibody Test at point-of-care hospitals (Cohen et al., 2003), Dola et al. reported that $22 \%$ of their study patients delivered within one hour after arrival to the labor and delivery unit, 31.6\% within 2 hours, 38.4\% within 3 hours, and $47.2 \%$ within 4 hours. Therefore, in order for any rapid HIV test to be of use, the test result turnaround time, the time for counseling, and the time to availability of the zidovudine treatment must be constricted to within a few hours after admission (Dola et al., 2010).

As a consequence, the full benefit of the rapid HIV tests may not be realized in patients who typically present without prenatal care - mostly in advanced labor and with rupture membranes (Dola et al., 2010). Due to the high prevalence of HIV infection in women without prenatal care (Lindsay et al., 1991), and until the rapid HIV testing results become available, obstetricians should consider these unregistered parturients as infected with HIV when they present for labor and delivery - refraining from certain common obstetrics practices (i.e. artificial rupture of membranes and the placement of an invasive fetal scalp electrode) to avoid inadvertly increasing the risk of perinatal transmission (Dola et al., 2010).

\section{HIV rescreening in late pregnancy - should all women be rescreened?}

A case report from Steele (Steele, 2010) describes three cases of infants whose mothers were screened negative for HIV infection in their first trimester of pregnancy. Since their mothers were not considered at high risk for HIV infection, they were not retested in the later stage of pregnancy according to the revised Centers for Disease Control and Prevention (CDC) guidelines (CDC, 2006; Branson et al., 2006). These mothers must have been infected with HIV later in their pregnancy as they were diagnosed with HIV infection shortly after delivery. Of these 3 infants, 2 developed an HIV infection (Steele, 2010).

The revised CDC guidelines (Branson et al., 2006) recommended repeat testing for HIV infection in late pregnancy but before 36 weeks of gestation for women at high risk for acquiring the infection. Women requiring repeat testing would include: those with high risk behaviors, those living in 20 states with high incidence of HIV infection, those receiving care at facilities with incidence of HIV infection of at least 1 per 1,000 women screened, and those with signs and symptoms consistent with acute HIV infection (Branson et al., 2006). These guidelines were placed as beneficial interventions to reduce mother-to-child transmission (MTCT) of HIV could have been implemented in mothers not identified as HIV infected until late in pregnancy or until the onset of labor (Wade et al., 1998).

Sansom et al, further supports the necessity of rescreening for HIV in the third trimester as it could prove to be cost-effective in preventing MTCT in a community with an HIV incidence of 1 per 1,000 person-years or higher. They argue that primary HIV infection may go undetected in women who continue to practice high-risk behaviors during pregnancy and in those with initial tests performed before HIV antibody development (Sansom et al., 2003). According to one study of $407 \mathrm{HIV}$-positive mothers, eight seroconversions happened after 
a negative test result during or just before pregnancy. Three of the 8 seroconversions resulted in perinatal HIV transmissions (Fiscus et al., 1999).

In an effort to further reduce perinatal transmission, Patterson et al. recommended that repeat HIV testing should be done in late pregnancy and again at time of labor and delivery along with the use of reflex RNA testing for women with negative antibody to detect acute HIV infection (Patterson et al, 2007). Furthermore, Gray et al reported that the risk of acquisition of HIV infection increased by 2 -fold in pregnancy after adjustment for behaviors risk factors (Gray et al., 2005). Although the evidence is inconclusive, this increased risk could be due to the hormonal changes in pregnancy, which could affect genital tract mucosa (Jacobson et al., 2000; Michael et al., 1997) or immune responses (Brahin, 2002; Beagley \& Gockel, 2003), resulting in susceptibility to HIV infectivity.

This above case report presented by Steele and the above arguments on cost-effectiveness of rescreening in late pregnancy support a recommendation for late pregnancy HIV screening possibly including RNA reflex testing for those with negative antibody to the virus- of all women instead of only women known to have risk factors. However, a barrier to putting this into practice is that not all insurance companies will cover the cost of a repeat HIV screening in late pregnancy for all pregnant women unless the CDC revises its guidelines (Steele, 2010).

\section{Cesarean section in HIV-infected women - Are there any maternal or neonatal morbidities?}

Scheduled cesarean section prior to labor is recommended at 38 weeks gestation for women with a viral load above 1,000 copies/ml to further prevent vertical transmission of HIV infection (American College of Obstetricians and Gynecologists [ACOG], 2004). The combination of cesarean delivery and antiretroviral medications have been demonstrated to effectively reduce mother-to-child transmission of HIV disease (The International Perinatal HIV Group, 1999; The European Mode of Delivery Collaboration, 1999;Mofenson, 2002; Burdge et al., 2003; Mandelbrot et al., 1998; Kind et al., 1998). Cesarean deliveries are not without significant complications even for HIV-negative women (Allen et al., 2003; Makoha et al., 2004). Therefore, HIV-positive women could theoretically be at greater risk for postoperative complications due to a relatively weakened immune system or immunodeficient status. However, there are conflicting reports from the currently available data with regard to post-cesarean morbidities incurred by HIV-infected women (The European Mode of Delivery Collaboration, 1999; Maiques-Montesinos et al., 1999; Grubert et al., 2002; Rodriguez et al., 2001; Marcollet et al., 2002; Watts et al., 2000). Most studies report an increased risk of post-operative morbidity, mostly infectious, in HIV-positive women compared with HIV-negative control subjects (Coll et al., 2002; Grubert el al., 1999; Vimercati et al., 2000). Additionally, the risk of complications is correlated with the degree of immunosuppression (Jamieson et al., 2007). Thus, those who most benefit from scheduled cesarean delivery to decrease vertical transmission would sustain the highest risk of complication from the procedure.

A Cochrane review (Read \& Newell; 2005) summarizes six studies (European Mode of Delivery Collaboration, 1999; Marcollet et al., 2002; Watts et al., 2000; Read et al., 2001; Faucher et al., 2001; Fior et al., 2004) which compare the complication rates in women receiving scheduled cesarean delivery, non-elective cesarean delivery, and vaginal delivery. Postoperative morbidity was highest in women who underwent a non-elective cesarean delivery. 
Vaginal delivery resulted in the lowest post-partum morbidity. Of note, most of these morbidities were post-operative fever, anemia, endometritis, and wound infection (Jamieson et al., 2007). Maternal deaths are rare, and these studies did not have adequate sample sizes to assess any potential differences in maternal mortality rate (Jamieson et al., 2007).

Given that these HIV-infected women are at high risk for post-operative infectious morbidities, prophylactic antibiotics should be given according to ACOG guidelines for all women who undergo cesarean delivery (American College of Obstetricians and Gynecologists [ACOG], 2003). However, most of these studies were performed prior to the recommendation to give prophylactic antibiotics at least 30 minutes prior to cesarean delivery instead of after cord clamping, which has been shown to decrease the risk of postoperative infection. It would be interesting to determine whether this newly recommended practice would reduce the risk of post-operative infection in these HIV-infected women.

Current ACOG guidelines recommends scheduled cesarean delivery in HIV infected women, emphasizing the importance of performing the surgery prior to the onset of labor or rupture of membranes to reduce the risk of vertical transmission (ACOG, 2004) and that cesarean delivery performed after the onset of labor or after rupture of membranes is of unclear benefit with regard to decreasing vertical transmission. Based on the previously mentioned data, these cesarean deliveries after onset of labor or after rupture of membrane could be associated with an increase in maternal infectious morbidity (Rodriguez et al., 2001; Marcollet et al., 2002; Read et al., 2001; Duarte et al., 2006). Therefore, when an HIVinfected woman attempts vaginal delivery, she should be counseled for the increased risk of post-operative morbidity should she require an emergent cesarean delivery (Cavasin et al., 2009). Marcollet et al. recommends that HIV-infected women with a low probability of having a successful vaginal delivery should consider a scheduled cesarean delivery (Marcollet et al., 2002).

Overall, as the cost for treating postpartum morbidity is relatively low in comparison to the cost incurred by pediatric HIV infection, it appears that scheduled cesarean delivery is costeffective (Halpern et al., 2000; Mrus et al., 2000; Ratcliffe et al., 1998).

ACOG recommends that scheduled cesarean delivery in the absence of medical or obstetrical indications should not be performed at less than 39 weeks of gestation, due to increased risk of neonatal respiratory morbidity (ACOG, 2001). This risk of respiratory morbidity for neonates born via cesarean section would closely approximate that of neonates born via the vaginal route at 39 weeks of gestation (Tita et al., 2009). In HIVinfected women with viral load greater than 1,000 copies/ml, both ACOG and the U.S. Public Health Service recommend scheduled cesarean delivery at 38 weeks for prevention of vertical transmission of the HIV infection (ACOG, 2001; Public Health Service Task Force, 2010). The gestational age of 38 weeks instead of 39 weeks was chosen as the timing for scheduled cesarean delivery with the intent to avoid spontaneous labor and rupture of membranes. Recent data reaffirmed an increased risk of neonatal morbidity even for those neonates born just a few days before 39 weeks of gestation (Tita et al., 2011). To address this valid clinical concern of a potential increase in neonatal respiratory distress syndrome in deliveries at 38 weeks in an effort to prevent mother-to-child transmission of HIV disease, Livingston et al and the IMPACT Protocol 1025 Study group (Livingston et al., 2010) performed a prospective cohort study. They concluded that after adjustment for gestational age and birth weight, the mode of delivery was not significantly associated with respiratory distress syndrome $(p=.10)$, although a trend toward an increased risk for respiratory distress syndrome was noted among neonates delivered by cesarean section (either elective and non- 
elective) when compared to those delivered via the vaginal route. The overall rate of neonatal respiratory distress syndrome among those born beyond 37 weeks by all modes of delivery is low: $3.4 \%$ for 37 weeks, $1.0 \%$ for 38 weeks, and $1.1 \%$ at 39 weeks. Among those neonates born via elective cesarean delivery at 38 weeks of gestation, there were only 2 out of 227 neonates who had respiratory distress syndrome. This is reassuring data and it appears that respiratory distress syndrome at this late gestational age could be readily managed, although, an admission to the intensive care nursery for treatment might invoke significant parental distress. In the counseling of patients on scheduled cesarean section at 38 weeks to prevent vertical transmission, one must include the small potential risk of neonatal respiratory distress syndrome. This small risk from iatrogenic premature delivery must then be balanced against the risk of less effective prevention of vertical transmission with the onset of labor or rupture of membranes if expectant management is continued until 39 weeks of gestation. The results from this study are the first available data and are reassuring with regard to the low rate of neonatal morbidity associated with current guidelines recommending scheduled cesarean delivery at 38 weeks, therefore further research in this area is needed to provide more robust data regarding this intervention for decreasing vertical transmission.

\section{The challenge of prenatal diagnosis in HIV infected - women}

The current standard of care offers prenatal diagnosis to the general obstetrics population. In pregnancies complicated by HIV infection, there is a suspicion of a higher rate of falsepositive results when these women are screened with the maternal serum multiple marker test (Yudin et al., 2003). This may lead to a higher risk for HIV infected women to require definitive testing with genetic amniocentesis. Therefore it is important to review the current data on the usefulness of biochemical marker screening test in pregnant HIV-infected women.

Variations in beta-hCG and AFP levels have been shown in HIV-infected pregnancies (Yudin et al., 2003; Einstein et al., 2004). This may make calculating the risk for Down syndrome difficult and might result in further diagnostic procedures. Additionally, a patient's immune status (CD4+ count) and viral load may be associated with abnormal screening test results (Neale et al., 2001; Gross et al., 2003). However, the mechanism for these alterations of the tested biochemical markers is unclear. It has been postulated to be due to the altered maternal immune status or the impact of highly active antiretroviral therapy on feto-maternal transfer of these markers, their metabolism or their excretion by the mother (Yudin et al., 2003).

In contrast to the above findings, Brossard et al (Brossard et al., 2008) concluded that these tests were still useful in a HIV-infected population composed of 214 women for first trimester screening tests and 209 women for risk assessment for neural tube defects. Although, they also found a lower median of the MoM of beta-human chorionic gonadotrophin and pregnancy-associated plasma protein-A in HIV-infected women when compared to controls, they did not believe that such differences impacted the risk estimation for Down syndrome or neural tube defects (Brossard et al., 2008).

Similarly, Le Meaux et al. studied a cohort of HIV-infected women in France and noted that untreated HIV-infection was associated with lower maternal alpha fetoprotein levels but there was no increase in false-positive rates in their double marker screening test (which included serum AFP and total beta-hCG levels) (Le Meaux et al., 2008). Therefore, future 
research - with larger sample sizes - is needed to further investigate the plausible mechanisms for the alterations in these biochemical markers in HIV-infected women.

If indeed HIV-infected women had a higher rate of false-positive maternal serum multiple marker screening test results it may warrant that they are more likely to require definitive diagnostic testing, which includes invasive procedures such as amniocentesis. Caution is required for HIV infected pregnant women who need amniocentesis because there is a potentially iatrogenic risk for perinatal transmission which might be related to elevated maternal viral load (Bucceri et al., 2001). Such invasive procedures might result in infected maternal blood leaking into the amniotic cavity as the needle is traversing the uterine wall or an anterior placenta (Giorlandino et al., 1996).

Data regarding the safety of prenatal diagnostic procedures - in pregnancies complicated by HIV infection - are scant and based on a very small number of participants. Older studies conducted prior to the widespread use of zidovudine suggest an increased risk of infecting the unborn child through invasive diagnostic tests - such as amniocentesis, amnioscopies and other needle puncture procedures (Mandelbrot et al., 1996). With the use of zidovudine and HAART, the risk of perinatal transmission from invasive diagnostic tests may be greatly reduced (Shapiro et al., 1999; Maiques et al., 2003). Other studies with small numbers of study patients (ranging from 6-11 women) reported no perinatal transmission in newborns (Bucceri et al., 2001; Ekoukou et al., 2008; Coll et al., 2006). In total, of the data collected from published studies, amongst the women who underwent invasive procedures there were 28 infected newborns from 82 women who did not receive antiretroviral treatment, 2 infected newborns from 24 women who received zidovudine treatment only, and no infected newborns from 78 women who received HAART treatment, $(p=0.0001)$ (Ekoukou et al., 2008). Thus, it appears that the significant decline in the rate of perinatal transmission after invasive procedures performed during pregnancy could possibly reflect the beneficial impact of anti-retroviral therapy (Ekoukou et al., 2008). Additionally, the potential risk of perinatal transmission might not be as great as it was once thought to be with the implementation of HAART. However, we must consider that the above studies are limited by their small number of study participants.

A policy to guide physicians to provide adequate counseling to HIV-infected women regarding the potential risks of early invasive prenatal diagnostic tests, and the optimal approach to such procedures is much needed. We venture to offer the following conclusions regarding prenatal diagnosis in HIV-infected women based on the above limited data. HIVinfected pregnant women should be offered biochemical marker testing for prenatal diagnosis since it is unclear whether the variations in these marker levels are significant. If invasive sampling of the amniotic fluid is warranted, then careful judgment must be used to consider the patient's risk factors for vertical transmission. Patient should be counseled that based on studies with small sample sizes, the risk of iatrogenic transmission of the HIV virus to the fetus is much lower than previously thought in the setting of optimal viral suppression and HAART. Ideally, patients undergoing invasive testing should be on antiretroviral therapy and have undetectable viral loads (Watts, 2002). Additionally, care should be taken to avoid penetrating the placenta during the procedure as this could theoretically increase maternal and fetal blood mixing, or directly inoculate the fetal blood (Giorlandino et al., 1996). Prenatal diagnosis should not be performed in women whose HIV serology is unknown, given the above concern of iatrogenic risk and the need for appropriate therapy prior to the procedure. There is a great need for continued investigations on which to establish future policy and protocol on this topic. 


\section{Management of PPROM in women infected with HIV}

The duration of rupture of membrane plays an important role in vertical transmission of HIV infection in term pregnancies. Minkoff et al. described a significantly increased rate of perinatal transmission of HIV infection in term women with low CD 4 count if they have ruptured their membranes for more than 4 hours (Minkoff et al., 1995). Other studies confirmed Minkoff's work and found an increase of perinatal transmission from $14 \%$ to $25 \%$ in the setting of rupture of membranes for greater than 4 hours (Landesman et al., 1996). Furthermore, there is a significant rise in transmission - from $8 \%$ to $31 \%$ - among women with AIDS if delivery is postponed past 24 hours after rupture of membranes (International Perinatal HIV Group, 2001).

These data reporting an increase in vertical transmission of the HIV infection after prolonged period of ruptured membranes pose a significant obstetrical dilemma for the management of women infected with HIV who had preterm premature rupture of the membranes (PPROM). The question is should all these HIV-infected women with PPROM be delivered at the time of first diagnosis with PPROM to avoid prolonged rupture of membranes, which potentially can lead to an increase in perinatal transmission of the disease? Does current data suggest that we should commit these HIV-infected pregnancies with PPROM to extreme prematurity with immediate delivery to avoid the risk of perinatal transmission of HIV? Available data on expectant management of PPROM in HIV infected women are limited. Currently available are two studies on PPROM in HIV infected women. The first study by Aagaard-Tillery et al. (Aagaard-Tillery et al. 2006) in 2006 evaluated the management and outcomes of 7 HIV pregnancies complicated by PPROM. They were diagnosed with PPROM, were expectantly management, and subsequently delivered between 25 to 32 weeks gestation. The mean latency for these patients was 17.1 days with a median of 5 days; one woman had a latency of 92 days. Two of 6 infants became infected with HIV through vertical transmission. The mothers of these two HIV-infected infants either did not receive antepartum or intrapartum antiretroviral therapy or only received treatment in the antepartum period with zidovudine monotherapy. Based on their results, the authors questioned whether expectant management is possible in the setting of PPROM in HIVinfected women, provided that they receive prophylactic combination antiretroviral therapy.

A second study in 2007 by Alvarez et al. (Alvarez et al., 2007) reported data on 18 cases of HIV infected women with PPROM at $\leq 34$ weeks of gestation from a single center, delivering at an average gestational age of 31 weeks. The latency period before delivery ranged from 4 to 336 hours. Of those cases, 10 patients had been managed with antenatal antiretroviral therapy and did not have mother-to-child-transmission of HIV regardless of the duration of ruptured membranes, viral load, or maternal CD4 count. The remaining 8 cases did not receive antenatal antiretroviral therapy and received only intrapartum nevirapine. Two of these eight neonates sustained perinatal transmission of HIV; their mothers did not have prenatal care and did not receive antenatal antiretroviral therapy. In this study, the perinatal transmission rate for HIV was $11.1 \%(2 / 18)$.

Although these two studies show encouraging outcomes and are very thought provoking, safety of expectant management of PPROM could not be ascertained based on the small number of study participants. From the above data, we concluded that for HIV-infected women with PPROM at a very young gestational age who has suppressed viral load and on antenatal HAART, expectant management to allow in-utero lung maturation might be considered. However, as risk of morbidity from preterm birth is decreased at tertiary care 
center beyond 30-32 weeks, there might be more advantageous for expedite delivery. The benefits of expectant management are still uncertain in patients not receiving antiretroviral treatment. Future studies on HIV infected women with PPROM prior to 34 weeks gestation are necessary to arrive at the optimal care plan.

\section{Could viral load in genital tract secretions have a role in perinatal transmission?}

Maternal viral load was determined to be the most important risk factor in perinatal transmission of HIV infection (The European Collaborative Study, 1999). Efforts in reduction of MTCT of HIV involve optimal suppression of viral load with the implementation of HAART. However, perinatal transmission was reported among women with undetectable maternal serum viral load (Cao et al., 1997; Sperling et al., 1996). Provocative data was gathered by the European Collaborative study. The investigators reported a $2 \%$ risk of vertical transmission among women with low viral load who delivered after 37 weeks by elective cesarean section and $11 \%$ among those delivered via the vaginal route (The European Collaborative Study, 1999). This might imply that other factors play an important role in the perinatal transmission besides maternal serum viral load. One explanation for the perinatal transmission in the setting of low plasma viral load and the protective effect from cesarean section could be that viral shedding in the female genital tract could have a role in perinatal transmission and that there might be a discordance between HIV-1 RNA levels in blood and cervicovaginal secretions (Garcia-Bujalance et al., 2004). HIV-1 RNA has been detected from the female cervicovaginal tract (Cu Uvin \& Caliendoa, 1997) and treatment with HAART can suppress HIV-1 RNA to below detectable levels in both the genital tract and plasma of non-pregnant women (Cu Uvin et al., 2000).

Several studies noted a strong correlation between the level of HIV-1 viral load in the genital tract and the plasma (Hart et al., 1999; Kovacs et al., 1999). However, in non-pregnant women with undetectable plasma viral load, HIV-1 RNA load can be found in their genital tract (Debiaggi et al., 2001). Conversely, some studies reported no correlation between the viral load in the plasma and genital shedding of non-pregnant women (Rasheed et al., 1996). One study from Kovacs et al. (Kovacs et al., 2001) reports that although there was a positive correlation between RNA concentrations in the plasma and the genital tract, $4 \%$ ( 9 of 252 women) of their population had higher RNA concentrations in the genital secretions and two women had at least 10-fold higher RNA levels in genital tract secretions than in plasma. Different genotypic variants of HIV-1 were found in the blood and cervicovaginal lavage according to another study (Shaheen et al., 1999). Garcia-Bujalance et al. reported 2 cases in 38 HIV-1 infected pregnant women with a low plasma viral load of $<50$ copies/mL but with detectable viral load in their vaginal secretions (Garcia-Bujalance et al., 2004).

Another factor in reducing MTCT of HIV infection can perhaps be determined by viral shedding in the female genital tract. The lack of correlation between the viral load in blood plasma and genital tract secretions might suggest that there is still risk for perinatal transmission in women with undetectable viral load in the plasma (Iribarren et al., 2001). More studies are needed to investigate on the roles of genital tract viral shedding in perinatal transmission and the possible benefit of using both plasma and cervicovaginal secretion viral loads despite undetectable viral plasma load in choosing the vaginal route of delivery. 


\section{Should assisted reproductive technology be available for HIV-infected men and women?}

Currently, about $80 \%$ of women infected with HIV are of reproductive age (CDC, 2001). With the current advent and widespread use of HAART in industrialized countries, HIV infection has become a chronic disease and those who are affected with the disease can now live longer and with a better quality of life (Kambin \& Batzer, 2004). Furthermore, with current interventions, the risk of MTCT of HIV infection is now significantly declined to approximately 2\% (The Ethics Committee of the American Society for Reproductive Medicine [ASRM], 2010). As a result, HIV-infected men and women may elect to have children. However, for discordant couple, reproduction may result in the risk of horizontal transmission to the uninfected partner.

The Ethics Committee of the American Society for Reproductive Medicine (ASRM) established guidelines in 1994 for patients infected with HIV who might request or require assisted reproductive technologies (Ethics Committee of the American Fertility Society, 1994). The committee made the following recommendations due to their concern about potential horizontal transmission to the uninfected partner and vertical transmission to the couple's child and the potential problem to the offspring as the infected parent might succumb to the disease. Their recommendations are as follows: couples seeking support are encouraged to test for HIV infection, development of written policies on infertility treatment for HIV-infected people by each institution, counseling of consequences of using infected sperm, and advising couples on the alternative options of donor sperm, adoption, or not having children (Ethics Committee of the American Fertility Society, 1994).

Since then, better understanding of the disease has been achieved, and the beneficial impact of HAART significantly improved survival and quality of life for HIV-infected persons, along with improved technique to provide virus-free sperm for reproductive assistance. Thus, in 2006, ASRM published its revision of the original guidelines. Obstetric health care providers should be aware of these revisions so that they can appropriately counsel their patients.

Approximately 1 in 500 - 1,000 episodes of unprotected intercourse is estimated to result in horizontal transmission of the HIV infection to an uninfected partner (Mandelbrot et al., 1997). Therefore, in discordant couples where the woman is infected with HIV and her partner is negative, ASRM discussed the use of homologous insemination with the uninfected male partner's sperm to achieve pregnancy and to avoid the risk of transmission (ASRM, 2010).

In discordant couples (with the male partner being infected), intercourse without condom use at the time of ovulation to attempt conception could reduce but does not eliminate the risk of infecting the partner. According to one study, the reported seroconversion rate was $4.3 \%$ for couples that employed timed intercourse to attempt conception (Sauer et al., 2009). Couples should be counseled against this unsafe method as they could still infect their partner. For these instances of male-infected sero-discordant couples, specific methods for sperm preparation and testing (density gradient and swim-up technique to obtain sperm and PCR virus detection assay) have been described (Kambin et al., 2004; Sauer et al., 2009; Semprini et al., 1998). The final sperm sample was used only if it tested negative on these assays (Semprini et al., 1998). These techniques resulted in less than 1\% of the samples testing positive for the virus and thus was discarded (Semprini et al., 1998). These techniques can markedly reduce the chance of HIV transmission to the female partner and 
child. Specifically, Semprini et al. reported data on almost 1,600 inseminations of $513 \mathrm{HIV}$ uninfected women in which there were 228 pregnancies. At a follow-up rate of $97.5 \%$ at 3 months, and $92 \%$ at one year, all mothers and children were uninfected (Semprini et al., 1998). Similarly, there was no report of transmitted HIV infection to the mother or child with intrauterine insemination (Kambin et al., 2004) or intracytoplasmic sperm injection (Sauer et al., 2009) technique. For these male-positive discordant couples, extensive counseling should be performed regarding transmission risk-reduction techniques (ASRM, 2000). Health care providers should not overlook HIV-infected men and women's desire to have children. They should make every effort to encourage these men and women to obtain care at the institutions with most effective methods to provide appropriate treatment and to reduce the chance of infecting their partner and child.

\section{Conclusion}

Significant progress was made in understanding HIV virology and important interventions were developed to reduce mother-to-child-transmission of this disease since the epidemic of this disease. Most obstetricians caring for HIV-infected women are familiar with these commonly employed interventions. However, there are still many difficult clinical situations where only scant data is available to direct management, in part due to the fortunately low prevalence of the disease in industrialized countries. We hope readers of this chapter would continue to report their challenging clinical encounters and thus, would contribute to the better care of these pregnant HIV-infected women. The review of these special considerations, hopefully, will aid obstetricians in their plan of care, raise valid questions, and suggest areas of future research directions.

\section{References}

Aagaard-Tillery, K., Lin, M.G., Lupo, V., Buchbinder, A., \& Ramsey, P.S. (2006). Clinical Study - Preterm Premature Rupture of Membranes in Human Immunodeficiency Virus Infected Women: A Novel Case Series. Infectious Diseases in Obstetrics and Gynecology; 2006:53234.

ACOG Committee on Obstetric Practice.(2004) Scheduled Cesarean Delivery and the Prevention of Vertical Transmission of HIV Infection. ACOG Committee Opinion No 234, May 2004.

Allen, V.M., O'Connell, C.M., Liston, R.M., \& Baskett, T.F. (2003). Maternal morbidity Associated with cesarean delivery without labor compared with spontaneous onset of labor at term. Obstet Gynecol 2003; 102:477-82.

Alvarez, J.R., Bardeguez, A, Iffy, L., \& Apuzzio, J.J.(2007). Preterm premature rupture of membranes in pregnancies complicated by human immunodeficiency virus infection: A single center's five-year experience. The Journal of Maternal-Fetal and Neonatal Medicine, 2007; 20(12):853-857.

American College of Obstetricians and Gynecologists. (2001). Scheduled cesarean delivery and the prevention of vertical transmission of HIV infection. ACOG Committee Opinion 234. Int J Gynaecol Obstet. 2001;73:279-81.

American College of Obstetricians and Gynecologists. (2003). Prophylactic antibiotics in labor and delivery: ACOG practice bulletin no. :47. Obstet Gynecol 2003;102:87582. 
Beagley, K.W., \& Gockel, C.M. (2003). Regulation of innate and adaptive immunity by female sex hormones oestradiol and progesterone. FEMS Immunol Med Microbiol, 2003;39:13-22.

Brabin L. (2002). Interactions of the female hormonal environment, susceptibility to viral infections, and disease progression. AIDS Patient Care STDS 2002; 16: 211-21.

Branson, B.M., Handsfield, H.H., Lampe, M.A., Janssen, R.S., Taylor, A.W., Lyss, S.B., et al. (2006). Revised recommendations for HIV testing of adults, adolescents, and pregnant women in health-care settings. MMWR Recomm Rep 2006;55(RR-14): 117.

Brossard, P., Boulvain, M., Coll, O., Barlow, P., Aebi-Popp, K., Bischof, P., Martinez de Teja, B. (2008). Swiss HIV Cohort Study; Swiss HIV Mother and Child Cohort Study. Is screening for fetal anomalies reliable in HIV-infected pregnant women? A multicentre study. AIDS, 2008;22(15):2013-7.

Bucceri, A.M., Somigliana, E., Vignali, M. (2001). Early invasive diagnostic techniques During pregnancy in HIV-infected women. Acta Obstet Gynecol Scand, 2001;80(1):82-3.

Bulterys, M., Jamieson, D.J., O'Sullivan, M.J., \& et al. (2004). Rapid HIV-1 Testing During Labor. A Multicenter Study. JAMA.2004;292:219-223.

Burdge, D.R., Money, D.M., Forbes, J.C., Walmsley, S.L., Smaill, F.M., Boucher, M., \& et al. (2003). Canadian consensus guidelines for the management of pregnancy, labour and delivery and for postpartum care in HIV-positive pregnant women and their offspring. CMAJ 2003; 168.

Cao, Y., Krogstad, P., Korber, B.T., et al. (1997). Maternal HIV-1 viral load and vertical transmission of infection: the Ariel Project for the prevention of HIV transmission from mother to infant. Nat Med, 1997;3:549-552.

Cavasin, H., Dola, T., Uribe, O., \& et al. (2009). Postoperative infectious morbidities of cesarean delivery in Human Immunodeficiency Virus-Infected Women. Infect Dis Obstet Gynecol. 2009;2009:827405. Epub 2009 May 25

Centers for Disease Control and Prevention (CDC). (2004). Rapid HIV Antibody Testing During Labor and Delivery for Women of Unknown HIV Status. A Practical Guide and Model Protocol. January 2004.

CDC. (2006). Sexually transmitted diseases treatment guidelines. Morb Mortal Wkly Rep, 2006;55(RR-11):14.

CDC. (2007). HIV/AIDS Fact sheet. Mother-to-Child (Perinatal) HIV transmission and prevention. October 2007.

CDC. (2001). HIV/ ADIS Surveillance Report. 2001;13.

Cohen, M.H., Olszewski, Y., Brandon, B., \& et al. (2003) Using point-of-care testing to make rapid HIV-1 tests in labor really rapid. AIDS. 2003;17:2121-2123.

Coll, O., Fiore, S., Floridia, M., \& et al. (2002). Pregnancy and HIV infection: a European consensus on management. AIDS, 2002; 16(suppl):S1-18.

Coll, .O, Suy, A., Hernandez, S., Pisa, S., Lonca, M., Thorne, C., \& Borrell, A. (2006). Prenatal diagnosis in human immunodeficiency virus-infected women: a new screening program for chromosomal anomalies. Am J Obstet Gynecol, 2006;194(1):192-8.

Connor, E.M., Sperling, R.S., Gelber, R., \& et al. (1994). Reduction of maternal-infant transmission of human immunodeficiency virus type 1 with zidovudine treatment. N. Engl J Med. 1994;331:1173-1180. 
Cu Uvin, S. \& Caliendoa, A.M. (1997). Cervicovaginal human immunodeficiency virus secretion and plasma viral load in human immunodeficiency virus-seropositive women. Obstetrics \& Gynecology, 1997;90(3): 739-743.

$\mathrm{Cu}$ Uvin, S., Caliendoa, A.M., Reinert, S., Chang, A., Juliano-Remollino, C., Flanigan, T.P., Mayer, K.H., \& Carpenter, C.C.J. (2000). Effect of highly active antiretroviral therapy on cervicovaginal HIV-1 RNA. AIDS, 2000;14:415-421.

Debiaggi, M., Zara, F., Spinillo, A., De Santolo ,A., Maserati, R., Bruno, R., Sacchi, P., Achilli, G., Pistorio, A., Romero, E., \& Filice, G. (2001). Viral excretion in cervicovaginal secretions of HIV-1 infected women receiving antiretroviral therapy. Eur J Clin, 2001; 20:91-96.

Dola, C.P., Tran, T., Duong, C., Federico, C., DeNicola, N., \& Maupin, R. (2010). Rapid HIV testing and obstetrical characteristics of women with unkown HIV serostatus at time of labor and delivery. J Natl Med Assoc. 2010; 102(12):1158-64.

Duarte, G., Read, J., Gonin, R., \& et al. (2006). Mode of delivery and postpartum morbidity in Latin American and Caribbean countries among women who are infected with human immunodeficiency virus-1: The NICHD International Site Development Initiative (NISDI) Perinatal Study. Am J Obstet Gynecol (2006) 195: 215-29.

Einstein, F.H., Wright, R.L., Trentacoste, S., Gross, S., Merkatz, I.R., \& Bernstein, P.S. (2004). The impact of protease inhibitors on maternal serum screening analyte levels in pregnant women who are HIV positive. Am J Obstet Gynecol, 2004;191(3):1004-8.

Ekoukou, D., Khuong-Josses, M.A., Ghibaudo, N., Mechali, D., \& Rotten, D. (2008). Amniocentesis in pregnant HIV-infected patients. Absence of mother-to-child viral transmission in a series of selected patients. Eur J Obstet Gynecol Reprod Biol, 2008;140(2):212-7. Epub 2008 Jun 27.

Ethics Committee of the American Fertility Society. (1994). Ethical considerations of assisted reproductive technologies. Fertil Steril 1994;62 (Suppl1):85s.

Ethics Committee of the American Society for Reproductive Medicine. (2010). Human immunodeficiency virus and infertility treatment. Fertility and Sterility, 2010;94(1): 11-15.

Faucher, P., Batallan, A., Bastian, H., \& et al. (2001). Management of pregnant women infected with HIV at Bichat Hospital between 1990 and 1998: analysis of 202 pregnancies. Gynecol Obstet Fertil 2001;29:211-25.

Fiore S, Newell ML, Thorne C. Higher rates of post-partum complications in HIV-infected than in uninfected women irresptive of mode of delivery. AIDS 2004;18:933-8

Fiscus SA, Adimora AA, Schoenbach VJ, McKinney R, Lim W, Rupar D, et al. Trends in human immunodeficiency virus (HIV) counseling, testing, and antiretroviral treatment of HIV-positive women and perinatal transmission in North Carolina. J Infect Dis 1999;180:99-105.

Fiscus SA, Schoenbach VJ, Wilfert C. Short courses of zidovudine and perinatal transmission of HIV. N Engl J Med. 1999 Apr 1; 340 (13): 1040 - 1.

García-Bujalance S, Ruiz G, De Guevara CL, Peña JM, Bates I, Vázquez JJ, Gutiérrez A. Quantitation of human immunodeficiency virus type 1 RNA loads in cervicovaginal secretions in pregnant women and relationship between viral loads in the genital tract and blood. Eur J Clin Microbiol Infect Dis.,2004;23(2):111-5. Epub 2004 Jan 20. 
Giorlandino C, Gambuzza G, D’Alessio P, Santoro ML, Gentili P, Vizzone A. Blood contamination of amniotic fluid after amniocentesis in relation to placental location. Prenat Diag, 1996;16:180-2

Gray R, Li X, Kigozi G, Serwadda D, Brahmbhatt H, Wabwire-Mangen F, et al. Increased risk of incident HIV during pregnancy in Rakai, Uganda: a prospective study. Lancet 2005; 366:1182-1188.

Gross S, Castillo W, Crane M, Espinosa B, Carter S, DeVeaux R, Salafia C. Maternal serum alpha-fetoprotein and human chorionic gonadotropin levels in women with human immunodeficiency virus. Am J Obstet Gynecol, 2003;188(4):1052-6.

Grubert TA, Reindell D, Belohradsky BH, Gurtler L, Stauber M, Dathe O. Rates of postoperative complication among human immunodeficiency virus-infected women who have undergone obstetric and gynecologic surgical procedures. CID 2002; 34:822-30.

Grubert TA, Reindell D, Kastner R, Lutz-Friedrich R, Belohradsky BH, Datha O. Complications after caesarean section in HIV-1 infected women not taking antiretroviral treatment. Lancet, 1999;354:1612-3.

Halpern MT, Read JS, Ganoczy DA, Harris Dr. Cost-effectiveness of cesarean section delivery to prevent mother-to-child transmission of HIV-1. AIDS 2000;14:691-700.

Hart CE, Lennox JL, Pratt-Palmore M, Wright TC, Schinazi RF, Evans-Strickfaden TE, Bush TJ, Schenell C, Conley LJ, Clancy KA, Ellerbrock TV. Correlation of human immunodeficiency virus type 1 RNA levels in blood and the female genital tract. J Infect Dis, 1999;179:871-882.

International Perinatal HIV Group. Duration of ruptured membranes and vertical transmission of HIV-1: A metaanalysis Bfrom 15 prospective cohort studies. AIDS 2001;15:357-368.

Iribarren JA, Ramos JR, Guerra L, Coll O, De Jose MI, Domingo P, Fortuny C, Miralles P, Parras F, Pena JM, Rodrigo C, Vidal R. Prevencion de la transmison vertical y tratamiento de la infeccion por el virus de la immunodeficiencia humana en la mujer embarazada. Enferm Infec Microbiol Clin, 2001;19:314-335.

Jacobson DL, Peralta L, Farmer M, Graham NMH, Gaydos C, Zenilman J. Relationship of hormonal contraception and cervical ectopy as measured by computerized planimetry to chlamydial infection in adolescents. Sex Transm Dis 2000; 27: 313-19.

Jamieson DJ, Read JS, Kourtis AP, Durant TM, Lampe MA, Dominguez KL. Cesarean delivery for HIV-infected women: recommendations and controversies. Am J Obstet Gynecol. 2007 Sep;197(3 Suppl):S96-100.

Kambin S, Batzer F. Assisted reproductive technology in HIV serodiscordant couples. Sex Reprod Menopause 2004;2:92-100.

Kind C, Rudin C, Siegrist C, Wyler C, Biedermann K, Lauper U. Prevention of vertical HIV transmission: additive protective effect of elective Cesarean section and zidovudine prophylaxis. AIDS 1998; 12:205-10.

Kogan, MD, Martin JA, Alexander GR, Kotelchuck M, Ventura SJ, Frigoletto FD. The changing pattern of prenatal care utilization in the US, 1981 - 1995, using different prenatal care indices. JAMA 1998; 279: 1623 - 8 .

Kovacs, A., Chan, L.S., Chen, Z.C., Meyer, W., Muderspach, L., Young, M., Anastos, K., \& Levine, A.M. (1999). HIV-1 RNA in plasma and genital tract secretions in women infected with HIV-1. J Acquir Immune Defic Syndr, 1999;22:124-131. 
Kovacs, A., Wasserman, S., Burns, D., Wright, D., Cohn, J., Landay, A., Weber, K., Cohen, M., Levine, A., Minkoff, H., Miotti, P., Palefsky, J., Young, M., Reichelderfer, P., \& the DATRI and WIHS Study Groups. (2001). Determinants of HIV-1 shedding in the genital tract of women. The Lancet, 2001;358(9293): 1593-1601.

Lancioni, C., Harwell, T., \& Rutstein, R.M. (1999). Prenatal care and HIV infection. AIDS Patient Care STDS. 1999 Feb; 13 (2); 97 - 102.

Landesman, S.H., Kalisha, L.A., Burns, D.N,. Minkoff, H,. Fox, H.E., Zorrilla, C., Garcia, P., Fowler, M.G., Mofenson, L., \& Tuomala, R. (1996). Obstetrical factors and the transmission of human immunodeficiency virus type 1 from mother to child. The Women and Infants Transmission Study. N Engl J Med, 1996;334:1617-1623.

Le Meaux, J.P., Tsatsaris, V., Schmitz, T., Fulla, Y., Launay, O., Goffinet, F., \& Azria, E. (2008). Maternal biochemical serum screening for Down syndrome in pregnancy with human immunodeficiency virus infection. Obstet Gynecol, 2008;112(2 Pt 1):223-30.

Lindsay, M.K., Feng, T.I., Peterson, H.B., \& et al. (1991). Routine human immunodeficiency infection screening in unregistered and registered inner-city parturients. Obstet Gynecol. 1991; 77: 599 - 603.

Livingston, E., Huo, Y., Patel, K., Brogly, S.B., Tuomala, R., Scott, G.B., Bardeguez, A., Stek, A., \& Read, J.S. (2010). For the International Maternal Pediatric Adolescent AIDS Clinical Trials Group (IMPAACT) Protocol 1025 Study. Mode of Delivery and Infant Respiratory Morbidity Among Infants Born to HIV-1 infected Women. Obstet Gynecol, 2010; 116(2 Pt 1): 335-343.

Maiques, V., García-Tejedor, A., Perales, A., Córdoba, J., \& Esteban, R.J. (2003). HIV detection in amniotic fluid samples. Amniocentesis can be performed in HIV pregnant women? Eur J Obstet Gynecol Reprod Biol, 2003;108(2):137-41.

Maiques-Montesinos, V., Cervera-Sanchez, J., Bellver-Pradas, J., Abad-Carrascosa, A., \& Serra, V. (1999). Post-cesarean section morbidity in HIV-positive women. Acta Obstet Gynecol Scand 1999; 78:789-92.

Makoha, F.W., Felimban, H.M., Fathuddien, M.A., Roomi, F., \& Ghabra, T. (2004). Multiple cesarean section morbidity. Int J Gynaecol Obstet 2004; 87:227-32.

Mandelbrot, L., Heard, I., Henrion-Geant, E., \& Henrion, R. (1997). Natural conception in HIV-negative women with HIV-infected partners. Lancet 1997;349:850-1.

Mandelbrot, L., Le Chenadec, J., Berrebi, A., Bongain, A., Bénifla, J.L., Delfraissy, J.F., \& et al. (1998). Perinatal HIV-1 transmission: interaction between zidovudine prophylaxis and mode of delivery in the French Perinatal Cohort. JAMA 1998; 280:55-60.

Mandelbrot, L., Mayaux, M.J., Bongain, A., Berrebi, A., Moudoub-Jeanpetit, Y., Bénifla, J.L., Ciraru Vigneron, N., Le Chenadec, J., Blanche, S., \& Delfraissy, J.F. (1996). Obstetric factors and mother-to-child transmission of human immunodeficiency virus type 1 : the French perinatal cohorts. SEROGEST French Pediatric HIV Infection Study Group. Am J Obstet Gynecol, 1996;175(3 Pt 1):661-7.

Marcollet, A., Goffinet, F., Firtion, G., Pannier, E., Le Bret, T., Brival, M., \& et al. (2002). Differences in postpartum morbidity in women who are infected with the human immunodeficiency virus after elective cesarean delivery, emergency cesarean delivery, or vaginal delivery. Am J Obstet Gynecol 2002; 186:784-9. 
Marks, G., Crepaz, N., \& Janssen, R.S. (2006). Estimating sexual transmission of HIV from persons aware and unaware that they are infected with the virus in the USA. AIDS 2006;20(10):1447-1450.

Michael, C.W. \& Esfahani, F.M. (1997). Pregnancy-related changes: a retrospective review of 278 cervical smears. Diagn Cytopathol 1997; 17: 99-107.

Minkoff, H., Burns, D.N., Landesman, S., Youchah, J., Goedert, J.J., Nugent, R.P., Muenz, L.R., \& Willoughby, A.D. (1995). The relationship of the duration of ruptured membranes to vertical transmission of human immunodeficiency virus. American Journal of Obstetrics and Gynecology, 1995;173:585-589.

Minkoff, H., McCalla, S., \& Feldman, J. (1990). The relationship of cocaine use to syphilis and HIV infection among inner city parturient women. Am J Obstet Gynecol. 1990;163:521-526.

Mofenson, L.M. (2002). U.S. Public Health Service Task Force Recommendations for use of antiretroviral drugs in pregnant HIV-1 -infected women for maternal health and interventions to reduce perinatal HIV-a transmission in the United States. MMWR Recomm Rep 2002; 51(RR-18):1-58.

Mrus, J.M., Goldi, S.J., Weinstein, M.C., \& Tsevat, J. (2000). The cost-effectiveness of elective cesarean delivery for HIV-infected women with detectable HIV RNA during pregnancy. AIDS, 2000;14:2543-52.

Neale, D., Magriples, U., Simpson, J., \& Copel, J. (2001). HIV and biochemical screening: Is there a higher false-positive rate in the HIV population? Am J Obstet Gynecol, 2001;185(suppl):S189.

Patterson, K.B., Leone, P.A., Fiscus, S.A., Kurue, J., McCoy, S.I., Wolf, L., Foust, E., Williams, D., Eron, J.J., \& Pilcher, C.D. (2007). Frequent detection of acute HIV infection in pregnant women. AIDS, 2007;21(17): 2303-2308.

Public Health Service Task Force. (2010). Recommendations for use of antiretroviral drugs In pregnant HIV-1-infected women for maternal health and interventions to reduce perinatal HIV-1 transmission in the United States. 2010. Available at: http:/ / aidsinfo.nih.gov/contentfiles/PerinatalGL.pdf Retrieved April 13, 2011.

Rasheed, S., Li, Z., Xu, D., \& Kovacs, A. (1996). Presence of cell-free human immunodeficiency virus in cervicovaginal secretions is independent of viral load in the blood of human immunodeficiency virus-infected women. Am J Obstet Gynecol, 1996;175:122- 130.

Ratcliffe, J., Ades, A.E., Gibb, D., Sculpher, M.J., \& Briggs, A.H. (1998). Prevention of mother-to-child transmission of HIV-1 infection: alternative strategies and their cost-effectiveness. AIDS 1998;12:1381-8.

Read, J.S. \& Newell, M.K. (2005). Efficacy and safety of cesarean delivery for prevention of mother-to-child transmission of HIV-1. Cochrane Database Syste Rev 2005;4:CD005479.

Read, J.S., Tuomala, R., Kpamegan, E., \& et al. (2001). Mode of Delivery and postpartum morbidity among HIV infected women: The Women and Infants Transmission Study. JAIDS March, 2001 26(3): 236-45.

Rodriguez, E.J., Spann, C., Jamieson, D., \& Lindsay, M. (2001). Postoperative morbidity associated with cesarean delivery among human immunodeficiency virus-positive women. Am J Obstet Gynecol 2001; 184:1108-11. 
Sansom, S., Jamieson, D., Farnham, P.G., Bulterys, M., \& Fowler, M.G. (2003). Humman Immunodeficiency Virus Retesting During Pregnancy: Costs and Effectiveness in Preventing Perinatal Transmission. Obstetrics \& Gynecology, 2003;102(4): 782-790.

Sauer, M.V., Wang, J.G., Douglas, N.C., Nakhuda, G.S., Vardhana, P., Jovanovic, V., \& Guarnaccia, M.M. (2009). Providing fertility care to men seropositive for human immunodeficiency virus: reviewing 10 years of experience and 420 consecutive cycles of in vitro fertilization and intracytoplasmic sperminjection. Fertil Steril 2009;91:2455-60.

Semprini, A.E., Levi-Setti, P., Ravizza, M., \& Pardi, G. (1998). Assisted conception to reduce the risk of male-to female sexual transfer of HIV in serodiscordant couples: an update [abstract]. Presented at the 1998 Symposium on AIDS in Women, Sao Paulo, Brazil, September 14-15, 1998.

Shaheen, F., Sison, A.V., McIntosh, L., Mukhart, M., \& Pomerantz, R.J. (1999). Analysis of HIV-1 in the cervicovaginal secretions and blood of pregnant and nonpregnant women. J Hum Virol, 1999;2:154-166.

Shapiro, D.E., Sperling, R.S., Mandelbrot, L., Britto, P., \& Cunningham, B.E. (1999). Risk factors for perinatal human immunodeficiency virus transmission in patients receiving zidovudine prophylaxis. Pediatric AIDS Clinical Trials Group protocol 076 Study Group. Obstet Gynecol, 1999;94(6):897-908.

Sperling, R.S., Shapiro, D.E., Cooms, R.W., \& et al. (1996). Maternal viral load, zidovuidine treatment, and the risk of transmission of human immunodeficiency virus type 1 from mother to infant. N Engl J Med, 1996;355:1621-1629.

Steele, R.W. (2010). Late Pregnancy Screening for Human Immunodeficiency Virus. The Pediatric Infectious Disease Journal, 2010: 72-73. E-pub ahead of print.

Stringer, J.S. \& Rouse, D.J. (1999). Rapid Testing and Zidovudine Treatment to Prevent Vertical Transmission of Human Immunodeficiency Virus in Unregistered Parturients: A Cost-Effectiveness Analysis. Obstetric \& Gynecology. 1999; 94:34-40.

The European Collaborative study. (1999). Maternal viral load and vertical transmission of HIV-1: an important factor but not the only one. AIDS, 1999;13(11): 1377-1385).

The European Mode of Delivery Collaboration. (1999). Elective caesarean-section versus Vaginal delivery in prevention of vertical HIV-1 transmission: A randomized clinical trial. Lancet 1999; 353:1035-9.

The International Perinatal HIV Group. (1999). The mode of delivery and the risk of vertical transmission of human immunodeficiency virus type 1: a meta-analysis of 15 prospective cohort studies. N Engl J Med 1999; 340:977-87.

Tita, A.T., Lai, Y., Landon, M.B., Spong, C.Y., Leveno, K.J., Varner, M.W., Caritis, S.N., Meis, P.J., Wapner, R.J., Sorokin, Y., Peaceman, A.M., O'Sullivan, M.J., Sibai, B.M., Thorp, J.M., Ramin, S.M., \& Mercer, B.M. (2011). Eunice Kennedy Shriver National Institute of Child Health and Human Development (NICHD) Maternal-Fetal Medicine Units Network (MFMU). Timing of elective repeat cesarean delivery at term and maternal perioperative outcomes. Obstet Gynecol, 2011;117(2 Pt 1):280-6

Tita, A.T., Landon, M.B., Spong, C.Y., Lai, Y., Leveno, K.J., Varner, M.W., Moawad, A.H., Caritis, S.N., Meis, P.J., Wapner, R.J., Sorokin, Y., Miodovnik, M., Carpenter, M., Peaceman, A.M., O'Sullivan, M.J., Sibai, B.M., Langer, O., Thorp, J.M., Ramin, S.M., Mercer, B.M.; Eunice Kennedy Shriver NICHD Maternal-Fetal Medicine Units 
Network. Timing of elective repeat cesarean delivery at term and neonatal outcomes. N Engl J Med, 2009;360(2):111-20.

Turner, B.J., McKee, L.J., Siverman, N.S., \&et al. (1996). Prenatal care and birth outcomes of a cohort of HIV-infected women. J Acquir Immune Defic Syndr 1996; 12:259 - 67.

Vimercati, A., Greco, P., Loverro, G., Lopalco, P.L., Pansini, V., \& Selvaggi, L. (2000). Maternal complications after caesarean section in HIV infected women. Eur J Obstet Gynecol Reprod Biol, 2000;90:73-76.

Wade, N.A., Birkhead, G.S., Warren, B.L., \& et al. (1998). Abbreviated regimens of zidovudine prophylaxis and perinatal transmission of the human immunodeficiency virus. N Engl J Med 1998; 339:1409-14.

Watts, D. (2002). Management of human immunodeficiency virus infection in pregnancy. N Engl J Med, 2002;346:1879-91.

Watts, D.H., Lambert, J.S., Stiehm, R., \& et al. (2000). Complications according to mode of delivery among human immunodeficiency virus-infected women with CDS lymphocyte counts of $\leq 500 / \mu \mathrm{L}$. Am J Obstet Gynecol July, 2000; 183 (1): 100-7.

Yudin, M.H., Prosen. T.L., \& Landers. D.V. (2003). Multiple-marker screening in human Immunodeficiency virus-positive pregnant women: Screen positivity rates with the triple and quad screens. Am J Obstet Gynecol, 2003;189(4):973-6. 


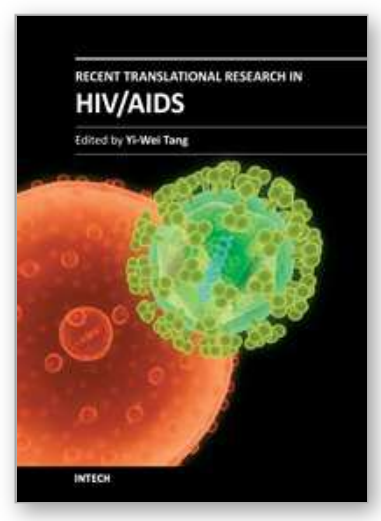

\author{
Recent Translational Research in HIV/AIDS \\ Edited by Prof. Yi-Wei Tang
}

ISBN 978-953-307-719-2

Hard cover, 564 pages

Publisher InTech

Published online 02, November, 2011

Published in print edition November, 2011

The collective efforts of HIV/AIDS research scientists from over 16 countries in the world are included in the book. This 27-chapter Open Access book well covers HIV/AIDS translational researches on pathogenesis, diagnosis, treatment, prevention, and also those beyond conventional fields. These are by no means inclusive, but they do offer a good foundation for the development of clinical patient care. The translational model forms the basis for progressing HIV/AIDS clinical research. When linked to the care of the patients, translational researches should result in a direct benefit for HIV/AIDS patients.

\title{
How to reference
}

In order to correctly reference this scholarly work, feel free to copy and paste the following:

Chi Dola, Sean Kim and Juliet Tran (2011). Special Considerations in the Management of HIV Infection in Pregnancy, Recent Translational Research in HIV/AIDS, Prof. Yi-Wei Tang (Ed.), ISBN: 978-953-307-719-2, InTech, Available from: http://www.intechopen.com/books/recent-translational-research-in-hiv-aids/specialconsiderations-in-the-management-of-hiv-infection-in-pregnancy

\section{INTECH}

open science | open minds

\section{InTech Europe}

University Campus STeP Ri

Slavka Krautzeka 83/A

51000 Rijeka, Croatia

Phone: +385 (51) 770447

Fax: +385 (51) 686166

www.intechopen.com

\section{InTech China}

Unit 405, Office Block, Hotel Equatorial Shanghai

No.65, Yan An Road (West), Shanghai, 200040, China

中国上海市延安西路65号上海国际贵都大饭店办公楼 405 单元

Phone: +86-21-62489820

Fax: +86-21-62489821 
(C) 2011 The Author(s). Licensee IntechOpen. This is an open access article distributed under the terms of the Creative Commons Attribution 3.0 License, which permits unrestricted use, distribution, and reproduction in any medium, provided the original work is properly cited. 